\title{
SARS-CoV-2 variants and environmental effects of lockdowns, masks and vaccination: a review
}

\author{
Shirin Akter ${ }^{1} \cdot$ Marzuka Ahmed Zakia $^{2} \cdot$ M. Mofijur ${ }^{3,4} \oplus$. Shams Forruque Ahmed ${ }^{5}$. Dai-Viet N. Vo ${ }^{6}$. \\ Gulam Khandaker $^{2,7}$.T. M. I. Mahlia ${ }^{3}$
}

Received: 17 August 2021 / Accepted: 7 September 2021 / Published online: 26 September 2021

(c) The Author(s), under exclusive licence to Springer Nature Switzerland AG 2021

\begin{abstract}
The severe acute respiratory syndrome coronavirus 2 (SARS-CoV-2) is continuously evolving and four variants of concern have been identified so far, including Alpha, Beta, Gamma and Delta variants. Here we review the indirect effect of preventive measures such as the implementation of lockdowns, mandatory face masks, and vaccination programs, to control the spread of the different variants of this infectious virus on the environment. We found that all these measures have a considerable environmental impact, notably on waste generation and air pollution. Waste generation is increased due to the implementation of all these preventive measures. While lockdowns decrease air pollution, unsustainable management of face mask waste and temperature-controlled supply chains of vaccination potentially increases air pollution.
\end{abstract}

Keywords SARS-CoV-2 $\cdot$ Delta variants $\cdot$ Face masks $\cdot$ COVID-19 vaccination $\cdot$ Environmental impact $\cdot$ Waste generation $\cdot$ Air pollution

\section{Abbreviations}

COVID-19 Coronavirus diseases

IATA International Air Transport Association

PPE

M. Mofijur

MdMofijur.Rahman@uts.edu.au

Shams Forruque Ahmed

shams.f.ahmed@gmail.com

1 Technical and Further Education (TAFE), Sydney, NSW 2135, Australia

2 Central Queensland Public Health Unit, Central Queensland Hospital and Health Service, Rockhampton, QLD 4700, Australia

3 Centre for Technology in Water and Wastewater, School of Civil and Environmental Engineering, University of Technology Sydney, Ultimo, NSW 2007, Australia

4 Mechanical Engineering Department, Prince Mohammad Bin Fahd University, Al Khobar 31952, Saudi Arabia

5 Science and Math Program, Asian University for Women, Chattogram 4000, Bangladesh

6 Center of Excellence for Green Energy and Environmental Nanomaterials (CE@GrEEN), Nguyen Tat Thanh University, Ho Chi Minh City 755414, Vietnam

7 Division of Research, Central Queensland University, Rockhampton, QLD 4701, Australia
SARS-CoV-2 Severe acute respiratory syndrome coronavirus 2

WHO World Health Organization

\section{Introduction}

SARS-CoV-2 is a positive-sense, single-stranded RNA virus (Alexandersen et al. 2020) (Fig. 1) that is responsible for the transmission of COVID-19 in humans. Viruses are constantly evolving, including SARS-CoV-2 which is responsible for the current COVID-19 pandemic (Lu et al. 2020). The World Health Organization (WHO) announced the variant naming system of SARS-CoV-2 on 1 June 2021 (Callaway 2021) and as of July 7, the WHO had identified four variants of concern: Alpha, Beta, Gamma and Delta (ACI 2021). Detailed information about the identified variants is presented in Fig. 2. Some variants have traits that influence transmission, disease severity, and vaccine efficacy. While the majority of genetic variations are harmless, some increase the mutant's capability of infecting cells or evading antibodies. Those "stronger" variants have the potential to outcompete other variants, resulting in their becoming the primary source of infections (Davies et al. 2021). Over the past year, a series of more transmissible variants have emerged, each containing a unique set of genetic mutations 
Fig. 1 Structure and entry in a cell of the severe acute respiratory syndrome coronavirus 2. Angiotensin-Converting Enzyme 2 (ACE2) is located on the membrane surface of host cells. The entry of the virus into host cells is mediated mainly by the use of spike protein. The lipid envelope is studded with several spike glycoproteins giving the virus a crown-like appearance. Reprinted with permission of Elsevier from (Naqvi et al. 2020)

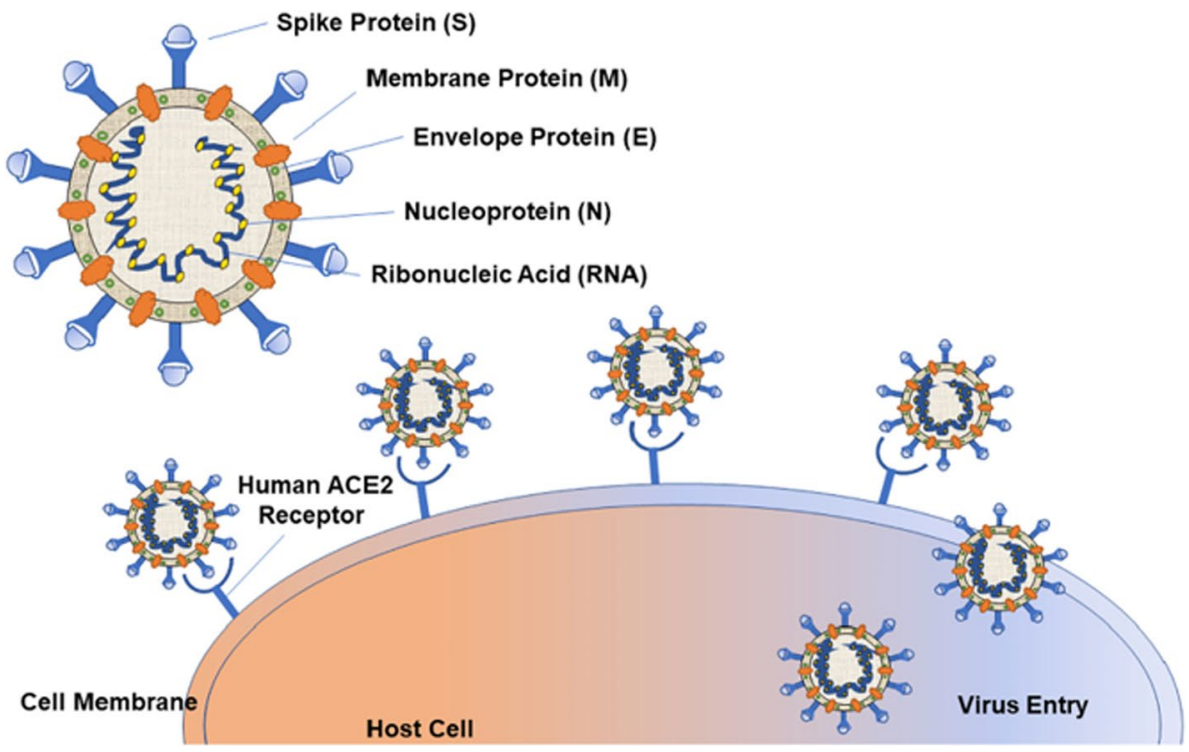

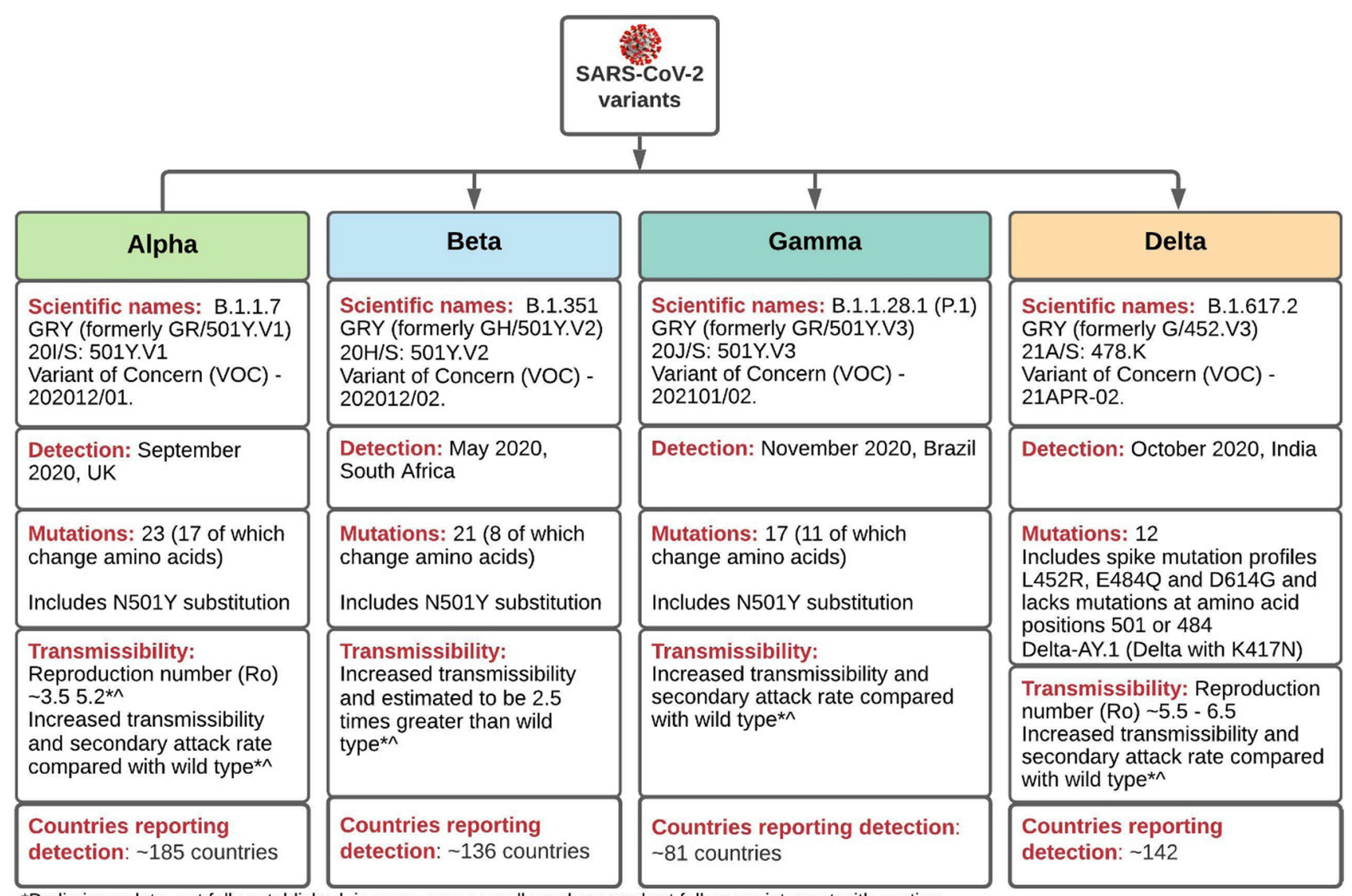

*Preliminary data, not fully established, in some cases small numbers or short follow up; interpret with caution

$\wedge$ Commentary literature, pre-peer review or news

Fig. 2 Scientific name, detection country, year of detection, mutation and transmissibility of different variants of severe acute respiratory syndrome coronavirus 2 (SARS-CoV-2) (ACI 2021). Four variants of concern including Alpha, Beta, Gamma and Delta have been identified so far

(Darby and Hiscox 2021). It has been a year of more transmissible variants, each with its mutations. The new Delta strain has numerous unusual spike protein alterations relative to other genetically similar variants, which is one of the 
reasons it is more alarming than earlier strains. The additional alterations may impact the spike's biology and thus its transmissibility.

However, SARS-CoV-2 and its variants are spreading at an alarming rate every day, and as of 12th August 2021, it has infected over 200 million people worldwide and more than 220 countries have reported confirmed cases now (Worldometer 2021). Figure 3 shows the worldwide distribution of SARS-CoV-2 cases. The most fundamental measure to limit the spread of different SARS-CoV-2 variants or prevent infection is to adhere to proper hygiene practices and to wear a facemask. In addition, several countries have implemented extremely stringent measures, such as school closures, the home-based office, and lockdowns to reduce the spread of COVID-19 outbreaks. The duration of lockdowns varies between countries and jurisdictions. Countries, states and territories determine the start and end dates of a lockdown based on the severity of the SARS-CoV-2 on their respective populations. There have been reports that due to the spread of different variants of SARS-CoV-2, some countries have extended lockdowns for several days or weeks and introduced the mandatory wearing of face masks, showing the continued intense influence of this disease on the public. Another preventive measure is the vaccine. Vaccines protect against the severity of illness, which helps to prevent hospitalization and death. All these preventive measures have both positive and negative environmental and societal impacts. This paper reviews how the preventive measures implemented to control the spread of different variants of SARS-CoV-2 is affecting the environment.

\section{Symptoms, severity, and transmission of different variants of SARS-CoV-2}

\section{Symptoms}

The behaviour of SARS-CoV-2 is evolving on a daily basis (Acter et al. 2020) and the characteristics of COVID-19 vary from person to person. People with a mild COVID-19 infection experience very mild symptoms or no symptoms at all (O'Keeffe et al. 2021). With a moderate infection, people experience coughing, shortness of breath, fever, generalised weakness, loss of appetite, and loss of smell. In addition, a
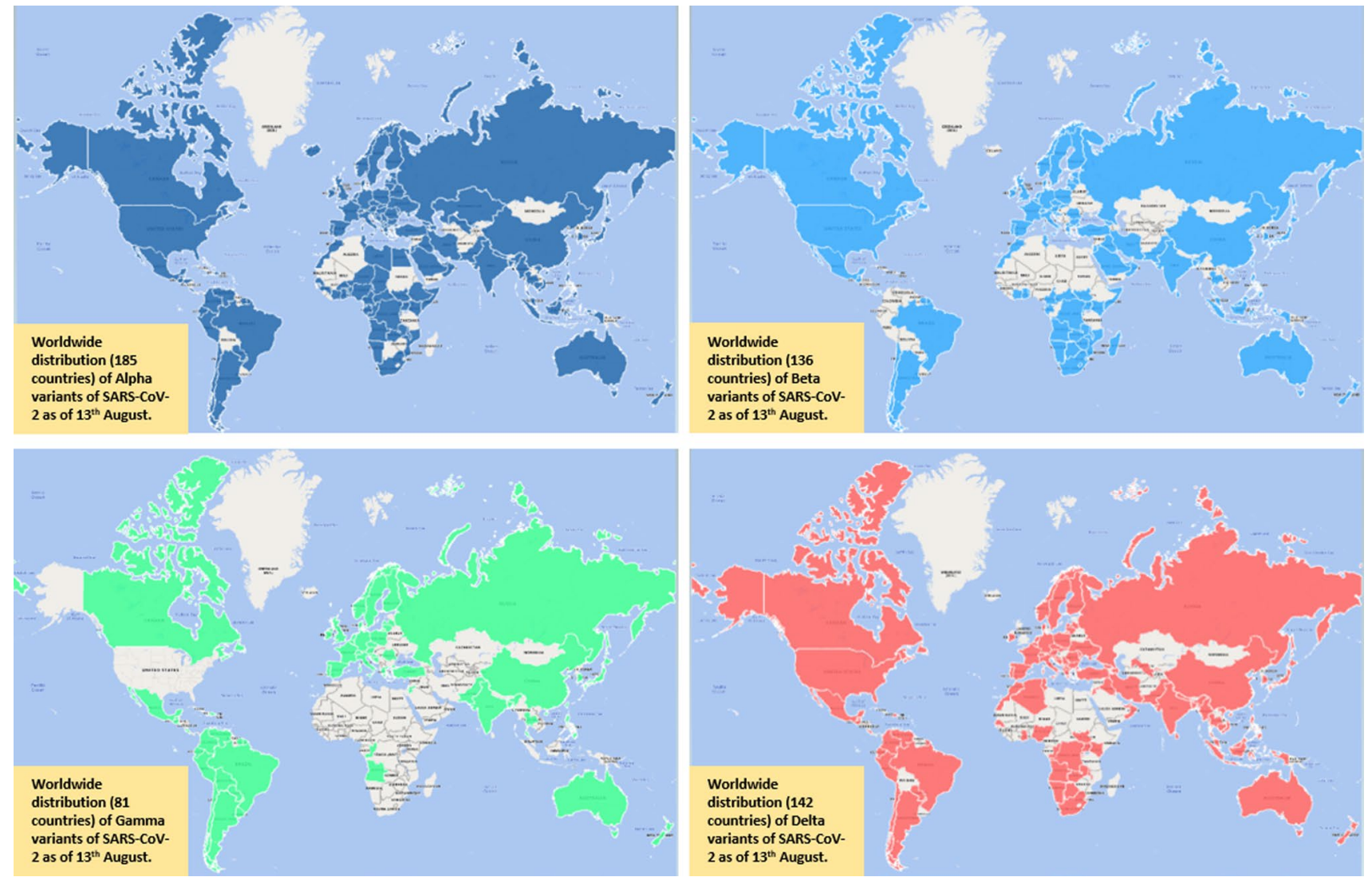

Fig. 3 Countries reporting variants Alpha, Beta, Gamma and Delta, as of $13^{\text {th }}$ August 2021. Worldwide 185 countries have reported Alpha, 136 countries Beta, 81 countries Gamma and 142 countries

Delta variants of severe acute respiratory syndrome coronavirus 2 (SARS-CoV-2, WHO, 2021). Map was created in Microsoft Excel using the data from World health Organisation 
sore throat, generalised body aches, myalgia or muscle pain, joint pain, headache, and GI upset are frequently experienced (Mofijur et al. 2020). Severe COVID-19 can result in a potentially fatal form of pneumonia (Harvard 2021). Children with COVID-19 experience the same symptoms as adults, albeit in a less severe form (Liguoro et al. 2020). The symptoms of the Delta variant are slightly different from those of the first variant that spread throughout the United States. It has been reported that the most common symptoms experienced by those with the Delta variant are headaches, sore throat, runny nose, and fever (CDC 2021). Coughing and anosmia (loss of smell) are also uncommon in COVID19 patients with the Delta variant.

\section{Severity}

SARS-CoV-2 is more likely to cause serious illness or death in older people and people with certain medical conditions (obesity, smokers, immunosuppressed people with diabetes, hypertension, heart disease, or cancer) (Engin et al. 2020). Down syndrome patients are at increased risk of hospitalisation or death due to the multiple comorbidities of Down syndrome. Because of existing health inequities linked to socioeconomic factors, some groups may be disproportionately affected by COVID-19 (Niedzwiedz et al. 2020). In addition to heart failure and cardiomyopathy, other medical conditions that may increase the risk of serious illness from different variants of SARS-CoV-2 include sickle cell disease, thalassemia, pregnancy, chronic liver disease and chronic lung diseases such as cystic or pulmonary fibrosis (Li et al. 2021).

\section{Rate and route of transmission}

The reproduction number is the number of secondary cases that can be infected by a primary case in a community without underlying immunity, vaccine, or preventive measures. The number of infected people is likely to increase when the reproduction number (infection rate) is greater than one (Inglesby 2020). In the case of SARS-CoV-2, the WHO estimated the reproduction number to be 1.4 to 2.559 , with additional research yielding a mean reproduction rate of 3.28 (Liu et al. 2020). Each primary case appears to be capable of infecting three other individuals. As the number of people infected increases, the effective reproductive number fluctuates until public health measures are put in place to contain the spread. As a result of new variants that emerge with different levels of transmissibility, the Rt can be influenced (O'Keeffe et al. 2021).

To infect a host cell, SARS-CoV-2 is thought to bind to angiotensin-converting enzyme- 2 receptors, which are found on epithelial cells in the airways, lungs, intestines, kidneys, or blood vessels, among other places in the body
(Cevik et al. 2020). A large proportion of the virus's replication occurs in the tissues of the upper respiratory tract. The route of SARS-CoV-2 transmission is presented in Fig. 4. Transmission of SARS-CoV-2 is primarily accomplished through prolonged close contact with an infected person, most commonly via the respiratory droplets formed during the talking, coughing, and sneezing of the infected person, or emitter. A second probable way of SARS-CoV-2 transmission is through contact with infected surfaces followed by touching the eyes, mouth, or nose. However, this is not thought to be the primary route of transmission (Dietz et al. 2020; O'Keeffe et al. 2021; Qian et al. 2020).

Susceptible people may encounter big droplets that are suspended in the air when they are in immediate contact with an emitter (Liu et al. 2017). According to current research, large droplets travel less than one metre before falling to the ground, so the risk of transmission increases if an infected person is within one metre of a susceptible host (O'Keeffe et al. 2021). Thus, a physical distance of $1.5 \mathrm{~m}$ has been established to prevent the spread of the disease in the community. Unlike large droplets, aerosols can remain suspended in the air for a longer period, allowing them to travel further distances (Fears et al. 2020). It has been reported that the SARS-CoV-2 remained viable for several hours within two metres of a COVID-19 patient (Jones et al. 2020).

\section{Preventive measures for limiting the spread of SARS-CoV-2}

Maintaining physical distance, avoiding travel, and wearing face masks are self-defence techniques (Chu et al. 2020; Liao et al. 2021). Several countries have already implemented preventive measures such as social distancing, stayat-home orders, mandatory face masks and vaccinations. COVID-19 vaccines are said to provide the best protection against all variants of SARS-CoV-2. Table 1 below compares the efficacy of various vaccines against different variants of SARS-CoV-2 (ACI 2021). The community health system strives to prevent SARS-CoV-2 transmission by limiting large gatherings. Crucial protective measures have been identified to stop the spread of SARS-CoV-2 such as wearing a face mask/personal protective equipment, implementing lockdowns, and vaccination (ACI 2021; Chowdhury et al. 2021; Mofijur et al. 2021b).

\section{Environmental impact of preventive measures that can limit the spread of SARS-CoV-2}

Protective measures have a direct or indirect environmental impact (Boroujeni et al. 2021) and Fig. 5 shows how these measures affect the environment (Rume and Islam 2020). In this study, environmental impacts including waste generation, air pollution and mobility reduction are highlighted. 


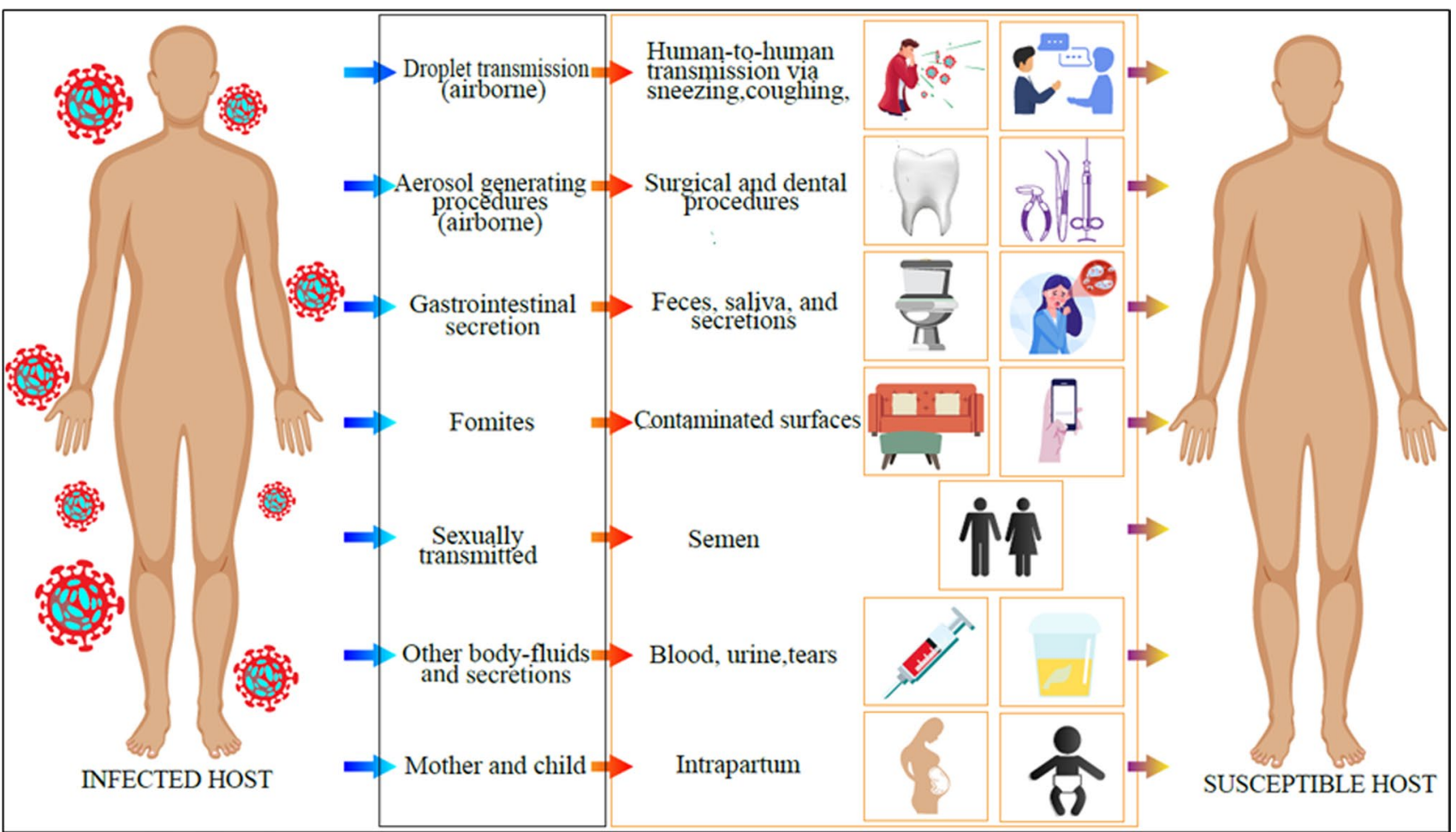

Fig. 4 Transmission route of the severe acute respiratory syndrome coronavirus 2 (SARS-CoV-2) from human to human (Karia et al. 2020). Severe acute respiratory syndrome coronavirus 2 can be trans-

\section{Waste generation}

Concerns about waste management have arisen as a result of the spread of the SARS-CoV-2 (Acter et al. 2020). Countries that have suffered significant consequences from COVID-19 are accustomed to providing services such as home isolation and pop-up confinement or quarantine. For at least two weeks after entering a country, some countries are using hotels to keep visitors confined. Due to quarantine measures in several countries, consumers have increased their domestic online shopping activity, which has resulted in increased household waste. Furthermore, because food purchased online is packaged, the amount of inorganic waste has also increased (Mofijur et al. 2021b).

Personal protective equipment (PPE) is now required or recommended in nearly every country to help combat the global spread of the SARS-CoV-2 (Boroujeni et al. 2021). The waste management system has been overwhelmed by single-use plastics, including massive amounts of PPE (Klemeš et al. 2020). For example, during the first outbreak, Wuhan hospitals generated 240 metric tonnes of medical waste, compared to 50 tonnes previously (Zambrano-Monserrate et al. 2020). But despite widespread bans on single-use plastics, the fight against the COVID19 pandemic suffers a setback (Naughton 2020). However, mitted from the infected host by droplet transmission, fomites, gastrointestinal secretion, and aerosol-generating pathway

like many other countries, during the lockdown in Sydney, it has been obligatory to wear a face mask. The number of face masks used in Sydney is not known with any precision. Accordingly, Eq. 1 proposed by (Nzediegwu and Chang 2020) has been applied to determine how many face masks are used every day in Sydney.

$D_{F M}=P \times U_{P} \times F_{M A R} \times F_{M G P}$

where $P$ is the population of Greater Sydney, which is about $8,172,000$ (ABS 2020); $U_{\mathrm{P}}$ denotes urban population in Sydney $(80 \%) ; F_{\mathrm{MAR}}$ denotes face masks acceptance rate (assumed $75 \%$ ), and $F_{\mathrm{MGP}}$ indicates the number of masks used by an individual on a daily basis (assumed 1). As a result, by employing Eq. 1 and the assumptions made above, the estimated daily face mask use in Sydney is 4,903,200. Given that a surgical mask weighs on average $30 \mathrm{~g}$, it is estimated that approximately 144 tonnes of used face masks are produced every day during the lockdown period.

In addition to reducing the spread of SARS-CoV-2, face masks raise serious environmental concerns about microplastic pollution. A single N95 mask contains approximately $11 \mathrm{~g}$ of polypropylene and/or other plastic derivatives, while a single surgical mask contains approximately $4.5 \mathrm{~g}$ (Akber Abbasi et al. 2020). If the thermoplastic 


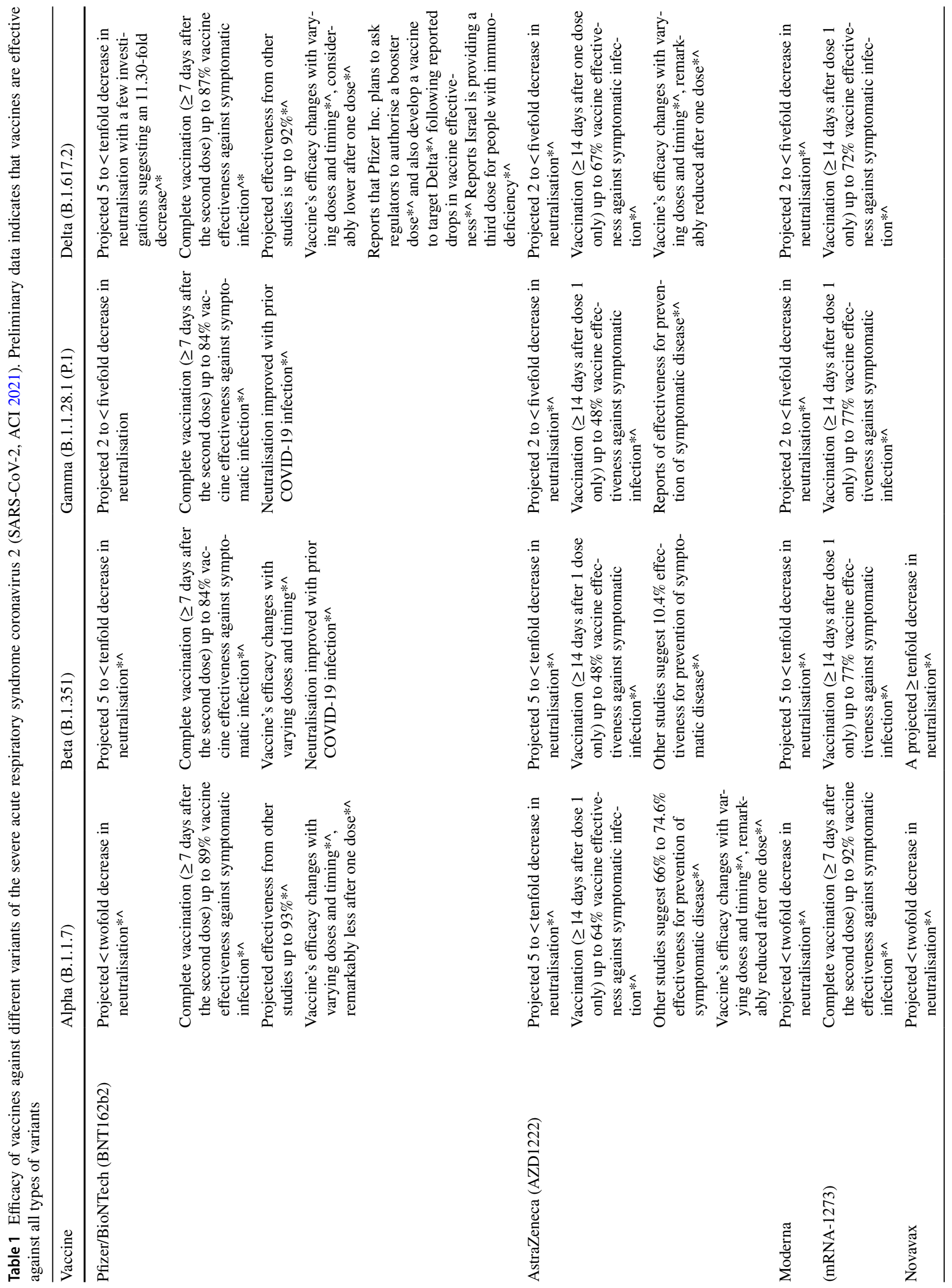




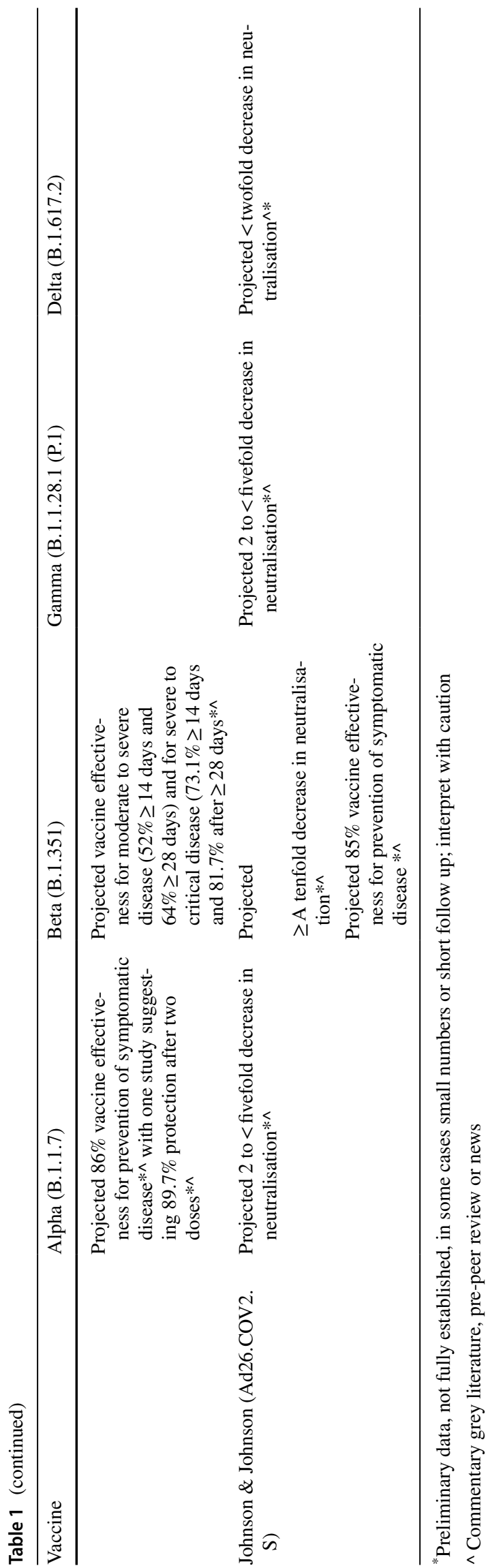

polymer fraction of this plastic content is exposed to high temperatures, ultraviolet light, and a change in $\mathrm{pH}$, it has the potential to degrade into tiny particles (microplastics) as shown in Fig. 6. The impact of microplastics on the aquatic environment and human health can be found in the literature (Mofijur et al. 2021a). Exceptional resistance, hydrophobic properties, molecular weight, and surface roughness make complete degradation/mineralization of polypropylene impossible. As a result, a majority of polypropylene ends up in the environment as microplastics.

Vaccination programs are large-scale operations requiring large numbers of vaccine units. Production capacity of approximately $10,000,000,000$ doses of vaccination to supply in different countries is expected to be achieved by 2021 , with 20 vaccine manufacturing companies participating in the process (Pagliusi et al. 2020). Waste is generated throughout the vaccination life cycle, including the application stage. Syringes, needles, vials, personal protective equipment, and plastic and cardboard/paper-based packaging materials are among the most common types of waste (Su et al. 2021). The vaccine itself also contributes, both as closed and open vial wastage. It has been found that between 0.3 and 30 percent of waste is related to COVID-19 vaccines (Klemeš et al. 2021). There are two main environmental issues associated with vaccination programs such as the management of solid and liquid waste.

\section{Air pollution}

Air quality has an impact on human health and comfort. Air pollution occurs when the concentration of solid particles, liquids, or gases in the air is high enough to cause environmental damage or adversely impact human health (Zhang et al. 2017). It is widely recognised that human activities are responsible for releasing most environmental pollutants (Manisalidis et al. 2020). Considering how widespread these activities are, they are by far the most significant contributors to air pollution. Some human activities, cleaning procedures and several natural sources have a minor impact on our environment (Jacobson and Jacobson 2002). However, lockdown measures implemented in response to the ongoing crisis have resulted in a significant reduction in economic activity, which has undoubtedly resulted in a reduction, albeit modest, in global greenhouse gas emissions.

Many countries or regions have enacted quarantines, entry bans, and other measures to protect their citizens from infection and to avoid the transmission of the SARS-CoV-2 (Mofijur et al. 2021b). Similarly, the New South Wales Government has implemented lockdown in Greater Sydney to lower the spread of the SARS-CoV-2. The implementation of lockdown in Sydney has reduced local air pollution. Figure 7 shows the comparison of particulate matter and ozone emission in the city of Sydney before and after lockdown. 


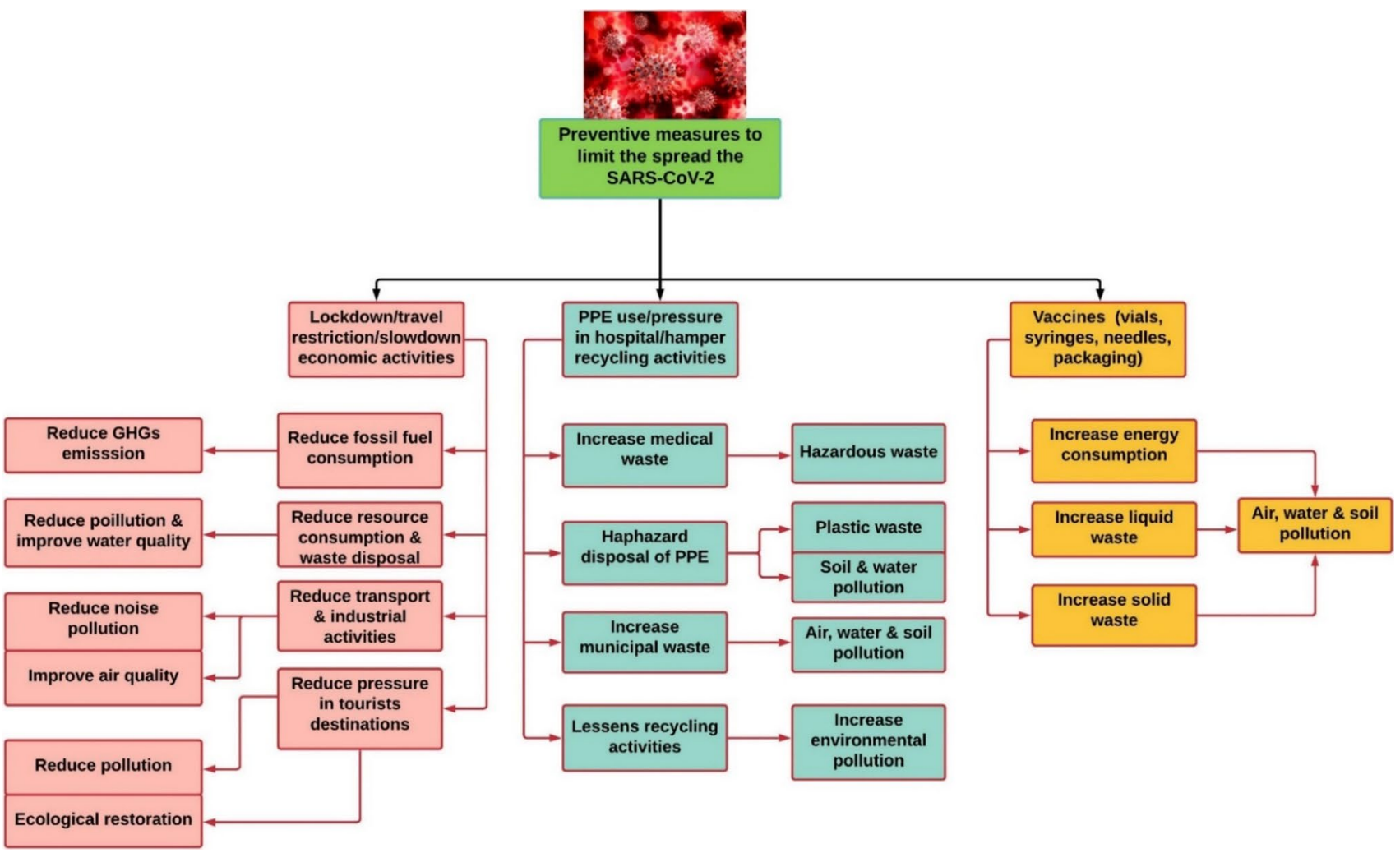

Fig. 5 Environmental impact of different protective measures including lockdown, wearing personal protective equipment (PPE) and vaccines to limit the spreading of different variants of severe acute respiratory syndrome coronavirus 2 (SARS-CoV-2). Lockdown lowers

air pollution, greenhouse gas emission (GHG) and improve air quality while vaccination increases energy consumption, waste generation, air, water and soil pollution

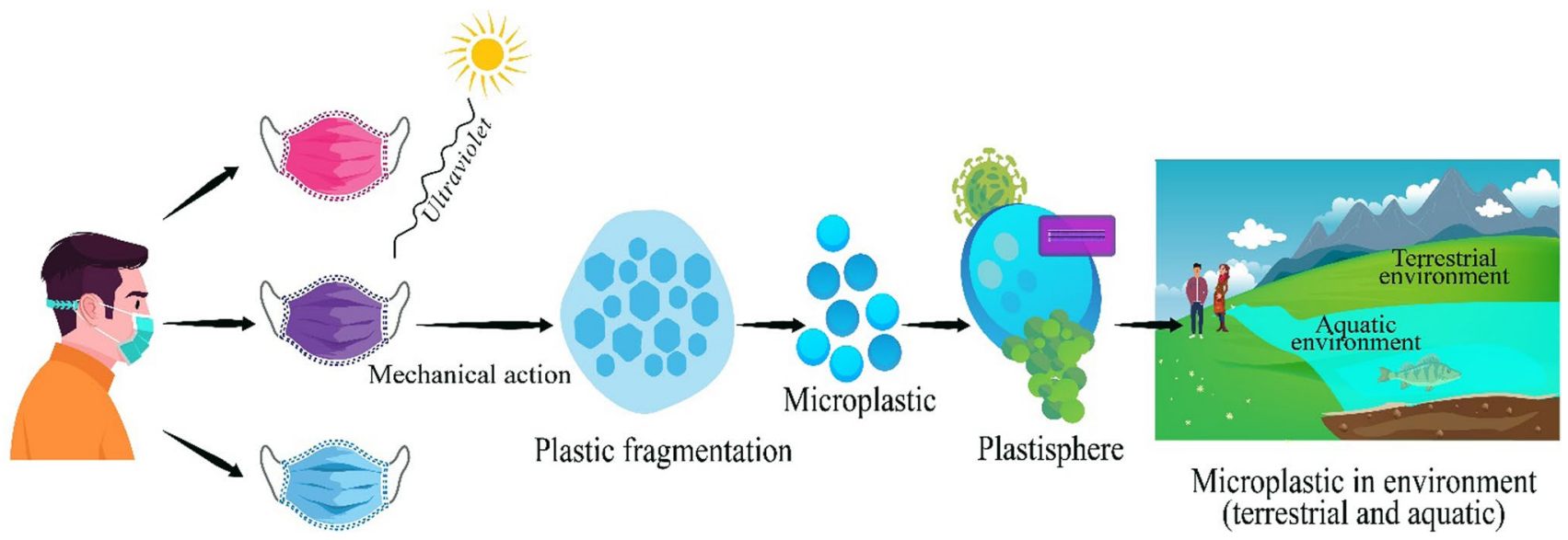

Fig. 6 Environmental fate of microplastics that originate from face masks (Akber Abbasi et al. 2020). Microplastic generated from facemasks due to ultraviolet light and high temperature can end up in the terrestrial and aquatic environment and affect human health and aquatic organisms

After the lockdown, it was discovered that average $\mathrm{PM}_{2.5}$ and $\mathrm{O}_{3}$ levels were reduced by $76 \%$ and $26 \%$, respectively, compared to the average $\mathrm{PM}_{2.5}$ and $\mathrm{O}_{3}$ levels before the lockdown.
Due to the COVID-19 pandemic, thousands of flights are not in operation which has lowered the global carbon emission but the reduction level is not enough that was expected. A significant increase in the environmental impact is caused 

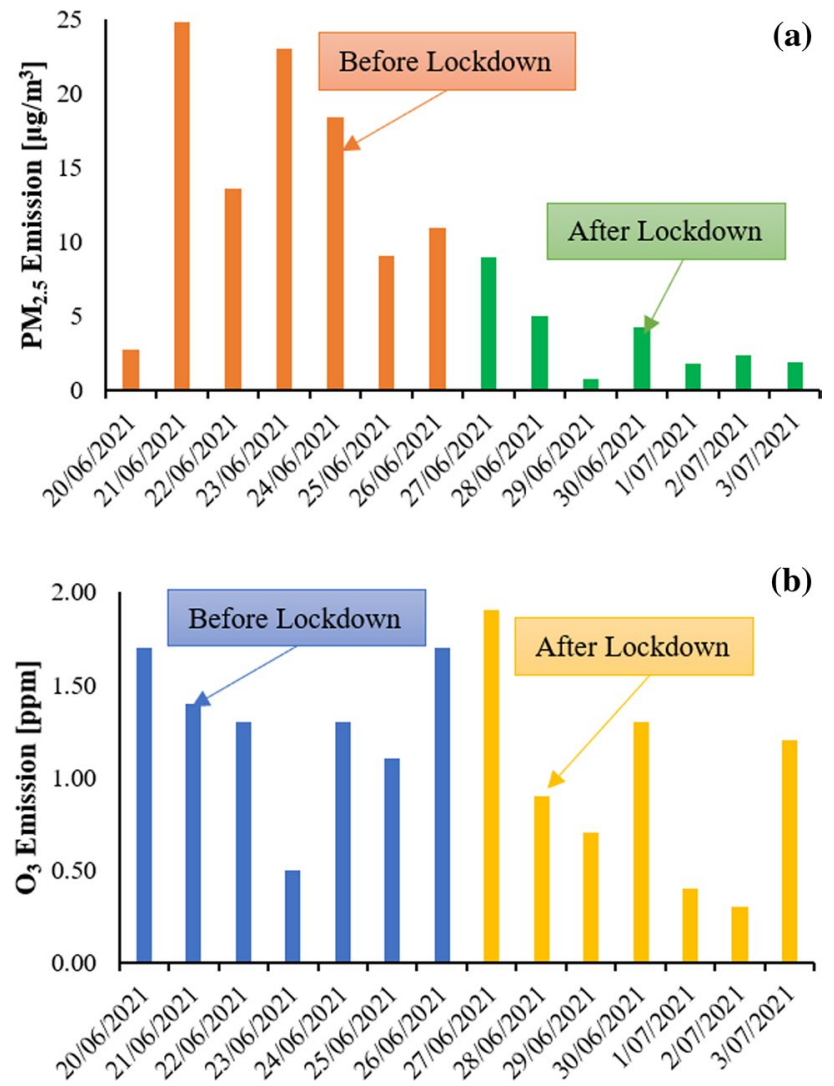

Fig. 7 Comparison of particulate matter $\left(\mathrm{PM}_{2.5}\right)$ and ozone $\left(\mathrm{O}_{3}\right)$ emission of Sydney city between before and after lockdown (NSW 2021). Both particulate matter and ozone have been decreased due to the implementation of lockdown in Sydney

by the production of a large number of vaccines. It is reasonable to expect that the temperature-controlled supply chains will generate significant emissions using aircraft, ships, and land transportation. To give an example, a total of $1,200,000,000$ doses of vaccines are planned to be produced and delivered alone by the pharmaceutical giant Pfizer by 2021, representing their largest immunisation campaign ever (Intelsius 2020). They intend to use 24 trucks and 20 flights to load and transport 7,600,000 doses/day in temperaturecontrolled packages (Paris and Hopkins 2020). Using the Boeing 747 (in cruise mode) as a model, 10-11 t of fuel is consumed per hour. In addition, an estimated 7.84 tonnes of fuel is consumed during take-off, climbing, and landing (Pearce 2021).

As estimated by the International Air Transport Association (IATA), a total of 8,000 Boeing 747 aircraft with full loads will be needed to vaccinate each of 7,800,000,000 people in the world (IATA 2020). However, two doses are realistic for each person, resulting in the engagement of 16,000 Boeing 747 aircraft with full payloads. Therefore, the total amount of fuel consumed would be between 768 and $832 \mathrm{kt}$. If one takes into account the conversion of carbon dioxide emissions and fuel-burning (i.e., approximately $3.03 \mathrm{t}$ of carbon dioxide is emitted for $1 \mathrm{t}$ of fuel-burning) (Pearce 2021), the total carbon dioxide emissions associated with COVID-19 vaccine flights would be in the range of approximately 2.38-2.57 Mt (Klemeš et al. 2021).

Based on the above global scenario, it can be calculated that about eight Boeing 747 aircraft with a full load are required to transport a single dose of vaccine for $8,172,000$ people in Sydney, and 16 fully loaded aircraft with two doses per capita. In addition, transferring the vaccine from the airport to the vaccination centres in cities and regional areas contributes to greenhouse gas emissions. Therefore, vaccination-related emissions have a significant impact on global air pollution from a transportation standpoint. The findings are based on the estimation only, exact calculation only can be made when more data is available.

\section{Mobility}

The implementation of the stay-at-home order in various countries has resulted in the cancellation of national and international programmes, the prohibition of travel to other countries, and the avoidance of unneeded gatherings. Similarly, because of the lockdowns and social distancing restrictions, peak-hour gridlocks in Sydney's most congested areas have been eliminated. Figure 8 depicts the shifts in mobility patterns in Sydney that occurred during the lockdown (Google 2021). In comparison to the period before Sydney's lockdown restrictions, it is evident mobility patterns have shifted considerably. Furthermore, the mobility trends for retail and recreation venues, public transportation hubs, and workplaces have significantly decreased because of the enforcement of restrictive rules, which include working from home, prohibiting non-essential movement, stay at home orders, and closing of shops, stores, and retail establishments. However, governments of different countries are encouraging their people to be vaccinated and people are allowed to go to the vaccination centre during the lockdown. Even though there is no exact data regarding the effect of vaccination programs on mobility but it is quite understandable that mobility due to the vaccination program is increased as many people are going to the centre for vaccination.

\section{Conclusion}

SARS-CoV-2 has posed serious threats to worldwide public health safety, and it continues to do so. Transmission of SARS-CoV-2 via the air has been identified as a highly prominent path. Among the variants, the Delta is a highly infectious and fast transmitting variant. However, different measures have been implemented to limit the spread and impact of SARS-CoV-2 and all of them have been effective 

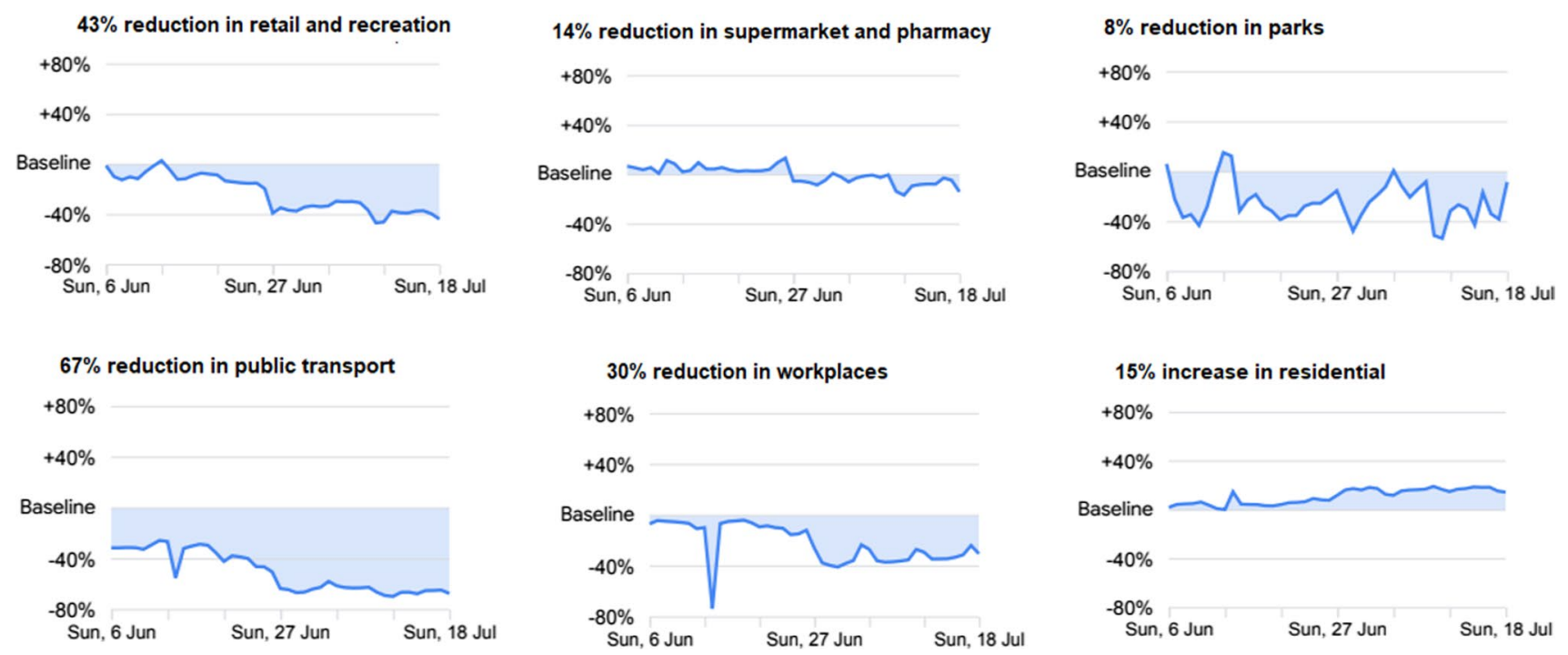

Fig. 8 Change of mobility patterns in Sydney due to the implementation of lockdown (Google 2021). The mobility due to lockdown in retail, supermarket, parks, public transport, and workplaces has been reduced up to $67 \%$ and residential mobility has been increased by $15 \%$

in controlling the spread of the virus. Examples include the fact that vaccines are still highly effective at preventing hospitalisation and death, even when used against the Delta variant of SARS-CoV-2. However, the indirect environmental impact of all these preventive measures is enormous, such as the massive waste generation. Therefore, it is important to take steps to reduce the environmental impact such as managing the waste sustainably.

\section{Declarations}

Conflict of interest The authors have no conflicts of interest to declare that are relevant to the content of this article.

\section{References}

ABS (2020) Australian Bureau of Statistics. National, state and territory population. Available from: https://www.abs.gov.au/stati stics/people/population/national-state-and-territory-population/ latest-release.

ACI (2021) Covid-19 Critical-intelligence-unit. Living Evidence SARS-CoV-2 variants. Retrieved 12th August. Available from: https://aci.health.nsw.gov.au/covid-19/critical-intelligenceunit/ sars-cov-2-variants

Acter T, Uddin N, Das J, Akhter A, Choudhury TR, Kim S (2020) Evolution of severe acute respiratory syndrome coronavirus 2 (SARSCoV-2) as coronavirus disease 2019 (COVID-19) pandemic: a global health emergency. Sci Total Environ 730:138996-138996. https://doi.org/10.1016/j.scitotenv.2020.138996

Akber Abbasi S, Khalil AB, Arslan M (2020) Extensive use of face masks during COVID-19 pandemic: (micro-)plastic pollution and potential health concerns in the Arabian Peninsula. Saudi J Biol Sci 27(12):3181-3186. https://doi.org/10.1016/j.sjbs.2020.09.054
Alexandersen S, Chamings A, Bhatta TR (2020) SARS-CoV-2 genomic and subgenomic RNAs in diagnostic samples are not an indicator of active replication. Nat Commun 11(1):6059. https://doi.org/10. 1038/s41467-020-19883-7

Boroujeni M, Saberian M, Li J (2021) Environmental impacts of COVID-19 on Victoria, Australia, witnessed two waves of Coronavirus. Environ Sci Pollut Res Int 28(11):14182-14191. https:// doi.org/10.1007/s11356-021-12556-y

Callaway E (2021) Coronavirus variants get Greek names — but will scientists use them? Nature 594:162. https://doi.org/10.1038/ d41586-021-01483-0

CDC (2021) Centres for disease control and prevention. Symptoms of COVID-19. Retrieved 12th August. Available from: https://www. cdc.gov/coronavirus/2019-ncov/symptoms-testing/symptoms.html

Cevik M, Kuppalli K, Kindrachuk J, Peiris M (2020) Virology, transmission, and pathogenesis of SARS-CoV-2. BMJ 371:m3862. https://doi.org/10.1136/bmj.m3862

Chowdhury MA, Shuvho MBA, Shahid MA, Haque AKMM, Kashem MA, Lam SS, Ong HC, Uddin MA, Mofijur M (2021) Prospect of biobased antiviral face mask to limit the coronavirus outbreak. Environ Res 192:110294

Chu DK, Akl EA, Duda S, Solo K, Yaacoub S, Schünemann HJ, Chu DK, Akl EA, El-harakeh A, Bognanni A, Lotfi T, Loeb M, Hajizadeh A, Bak A, Izcovich A, Cuello-Garcia CA, Chen C, Harris DJ, Borowiack E, Chamseddine F, Schünemann F, Morgano GP, Muti Schünemann GEU, Chen G, Zhao H, Neumann I, Chan J, Khabsa J, Hneiny L, Harrison L, Smith M, Rizk N, Giorgi Rossi P, AbiHanna P, El-khoury R, Stalteri R, Baldeh T, Piggott T, Zhang Y, Saad Z, Khamis A, Reinap M, Duda S, Solo K, Yaacoub S, Schünemann HJ (2020) Physical distancing, face masks, and eye protection to prevent person-to-person transmission of SARSCoV-2 and COVID-19: a systematic review and meta-analysis. The Lancet 395(10242):1973-1987. https://doi.org/10.1016/ S0140-6736(20)31142-9

Darby AC, Hiscox JA (2021) Covid-19: variants and vaccination. BMJ 372:n771. https://doi.org/10.1136/bmj.n771

Davies NG, Abbott S, Barnard RC, Jarvis CI, Kucharski AJ, Munday JD, Pearson CAB, Russell TW, Tully DC, Washburne AD, Wenseleers T, Gimma A, Waites W, Wong KLM, van Zandvoort 
K, Silverman JD, Group CC-W, Consortium C-G U, Diaz-Ordaz K, Keogh R, Eggo RM, Funk S, Jit M, Atkins KE, Edmunds WJ (2021) Estimated transmissibility and impact of SARS-CoV-2 lineage B.1.1.7 in England. Science, 372(6538), eabg3055. https://doi.org/10.1126/science.abg3055

Dietz L, Horve PF, Coil DA, Fretz M, Eisen JA, Wymelenberg KVD, Gilbert JA (2020) 2019 Novel Coronavirus (COVID-19) pandemic: built environment considerations to reduce transmission. mSystems, https://doi.org/10.1128/mSystems.00245-20

Engin AB, Engin ED, Engin A (2020) Two important controversial risk factors in SARS-CoV-2 infection: Obesity and smoking. Environ Toxicol Pharmacol 78:103411. https://doi.org/10. 1016/j.etap.2020.103411

Fears A, Klimstra W, Duprex P, Hartman A, Weaver S, Plante K, Mirchandani D, Plante JA, Aguilar P, Fernández D, Nalca A, Totura A, Dyer D, Kearney B, Lackemeyer M, Bohannon JK, Johnson R, Garry R, Reed D, Roy C (2020) Persistence of severe acute respiratory syndrome Coronavirus 2 in aerosol suspensions. Emerging Infect Dis J 26(9):2168. https://doi.org/ 10.3201/eid2609.201806

Google (2021) Covid 19 Community mobility reports. Retrieved 16th July. https://www.gstatic.com/covid19/mobility/2021-07 16_AU_ New_South_Wales_Mobility_Report_en-GB.pdf.

Harvard (2021) COVID-19 basics. Symptoms, spread and other essential information about the new coronavirus and COVID-19. Boston, MA. Harvard Medical School. Harvard Health Publishing. Retrieved 10th August. Available from: https://www.health.harva rd.edu/diseases-and-conditions/covid-19-basics

IATA (2020) The time to prepare for COVID-19 vaccine transport is now. International air transport association (IATA). Available from: https://www.iata.org/en/pressroom/pr/2020-09-09-01/. Retrieved 10th August.

Inglesby TV (2020) Public health measures and the reproduction number of SARS-CoV-2. JAMA 323(21):2186-2187. https://doi.org/ 10.1001/jama.2020.7878

Intelsius (2020) The environmental impact of COVID-19. Available from: https://intelsius.com/news/the-environmental-impact-ofcovid-19/. Retrieved 12th August.

Jacobson MZ, Jacobson MZ (2002) Atmospheric pollution: history, science, and regulation. Cambridge University Press

Jones NR, Qureshi ZU, Temple RJ, Larwood JPJ, Greenhalgh T, Bourouiba L (2020) Two metres or one: what is the evidence for physical distancing in covid-19? BMJ 370:m3223. https://doi.org/10. 1136/bmj.m3223

Karia R, Gupta I, Khandait H, Yadav A, Yadav A (2020) COVID-19 and its modes of transmission. SN Compre Clin Med 2(10):17981801. https://doi.org/10.1007/s42399-020-00498-4

Klemeš JJ, Fan YV, Tan RR, Jiang P (2020) Minimising the present and future plastic waste, energy and environmental footprints related to COVID-19. Renew Sustain Energy Rev 127:109883. https:// doi.org/10.1016/j.rser.2020.109883

Klemeš JJ, Jiang P, Fan YV, Bokhari A, Wang X-C (2021) COVID-19 pandemics Stage II - energy and environmental impacts of vaccination. Renew Sustain Energy Rev 150:111400. https://doi.org/ 10.1016/j.rser.2021.111400

Li X, Zhong X, Wang Y, Zeng X, Luo T, Liu Q (2021) Clinical determinants of the severity of COVID-19: a systematic review and meta-analysis. PLoS ONE 16(5):e0250602. https://doi.org/10. 1371/journal.pone.0250602

Liao M, Liu H, Wang X, Hu X, Huang Y, Liu X, Brenan K, Mecha J, Nirmalan M, Lu JR (2021) A technical review of face mask wearing in preventing respiratory COVID-19 transmission. Curr Opin Colloid Interface Sci 52:101417. https://doi.org/10.1016/j. cocis.2021.101417

Liguoro I, Pilotto C, Bonanni M, Ferrari ME, Pusiol A, Nocerino A, Vidal E, Cogo P (2020) SARS-COV-2 infection in children and newborns: a systematic review. Eur J Pediatr 179(7):1029-1046. https://doi.org/10.1007/s00431-020-03684-7

Liu L, Li Y, Nielsen PV, Wei J, Jensen RL (2017) Short-range airborne transmission of expiratory droplets between two people. Indoor Air 27(2):452-462. https://doi.org/10.1111/ina.12314

Liu Y, Gayle AA, Wilder-Smith A, Rocklöv J (2020) The reproductive number of COVID-19 is higher compared to SARS coronavirus. J Travel Med. https://doi.org/10.1093/jtm/taaa021

Lu R, Zhao X, Li J, Niu P, Yang B, Wu H, Wang W, Song H, Huang B, Zhu N (2020) Genomic characterisation and epidemiology of 2019 novel coronavirus: implications for virus origins and receptor binding. The Lancet 395(10224):565-574. https://doi.org/10. 1016/S0140-6736(20)30251-8

Manisalidis I, Stavropoulou E, Stavropoulos A, Bezirtzoglou E (2020) Environmental and health impacts of air pollution: a review [review]. Front Public Health. https://doi.org/10.3389/fpubh. 2020.00014

Mofijur M, Ahmed SF, Rahman SMA, Arafat Siddiki SKY, Islam ABMS, Shahabuddin M, Ong HC, Mahlia TMI, Djavanroodi F, Show PL (2021) Source, distribution and emerging threat of micro- and nanoplastics to marine organism and human health: Socio-economic impact and management strategies. Environ Res 195:110857. https://doi.org/10.1016/j.envres.2021.110857

Mofijur M, Fattah IMR, Alam MA, Islam ABMS, Ong HC, Rahman SMA, Najafi G, Ahmed SF, Uddin MA, Mahlia TMI (2021) Impact of COVID-19 on the social, economic, environmental and energy domains: lessons learnt from a global pandemic. Sustain Prod Consump 26:343-359. https://doi.org/10.1016/j.spc.2020. 10.016

Mofijur M, Rizwanul Fattah IM, Saiful Islam ABM, Uddin MN, Ashrafur Rahman SM, Chowdhury MA, Alam MA, Uddin MA (2020) Relationship between weather variables and new daily COVID-19 cases in dhaka Bangladesh. Sustainability 12(20):8319

Naqvi AAT, Fatima K, Mohammad T, Fatima U, Singh IK, Singh A, Atif SM, Hariprasad G, Hasan GM, Hassan MI (2020). Insights into SARS-CoV-2 genome, structure, evolution, pathogenesis and therapies: structural genomics approach. Biochimica et Biophysica Acta (BBA) Molecular Basis of Disease, 1866(10), 165878. https://doi.org/10.1016/j.bbadis.2020.165878

Naughton CC (2020) Will the COVID-19 pandemic change waste generation and composition?: The need for more real-time waste management data and systems thinking. Resour Conserv Recycl 162:105050-105050. https://doi.org/10.1016/j.resconrec.2020. 105050

Niedzwiedz CL, O’Donnell CA, Jani BD, Demou E, Ho FK, CelisMorales C, Nicholl BI, Mair FS, Welsh P, Sattar N, Pell JP, Katikireddi SV (2020) Ethnic and socioeconomic differences in SARS-CoV-2 infection: prospective cohort study using UK Biobank. BMC Med 18(1):160. https://doi.org/10.1186/ s12916-020-01640-8

NSW. (2021). Department of planning, industry and environment. Air quality concentration data

Nzediegwu C, Chang SX (2020) Improper solid waste management increases potential for COVID-19 spread in developing countries. Resour Conserv Recycl 161:104947-104947. https://doi.org/10. 1016/j.resconrec.2020.104947

O'Keeffe J, Freeman S, Nicol A (2021) National collaborating centre for environmental health (NCCEH). The basics of SARS-CoV-2 transmission. Vancouver, BC: NCCEH.

Pagliusi S, Jarrett S, Hayman B, Kreysa U, Prasad SD, Reers M, Thai PH, Wu K, Zhang YT, Baek YO (2020) Emerging manufacturers engagements in the COVID- 19 vaccine research, development and supply. Vaccine 38(34):5418-5423. https://doi.org/10.1016/j. vaccine.2020.06.022

Paris C, Hopkins J (2020) Pfizer sets up its 'biggest ever' vaccination distribution campaign. Available from: https://www.wsj.com/artic 
les/pfizer-sets-up-its-biggest-ever-vaccination-distribution-campa ign-11603272614. Retrieved 30th July.

Pearce, C. (2021). How many cars equal the CO2 emissions of one plane? Available from: https://www.sciencefocus.com/futuretechnology/how-many-cars-equal-the-co2-emissions-of-oneplane/. Retrieved 20th July.

Qian G, Yang N, Ma AHY, Wang L, Li G, Chen X, Chen X (2020) COVID-19 transmission within a family cluster by presymptomatic carriers in China. Clin Infect Dis 71(15):861-862. https:// doi.org/10.1093/cid/ciaa316

Rume T, Islam SMD-U (2020) Environmental effects of COVID19 pandemic and potential strategies of sustainability. Heliyon. https://doi.org/10.1016/j.heliyon.2020.e04965

Su G, Ong HC, Ibrahim S, Fattah IMR, Mofijur M, Chong CT (2021) Valorisation of medical waste through pyrolysis for a cleaner environment: Progress and challenges. Environ Pollut 279:116934. https://doi.org/10.1016/j.envpol.2021.116934
Worldometer. (2021). COVID-19 Coronavirus pandemic. Accessed on 13th August 2021. Available from: https://www.who. $\mathrm{int} /$ publications/m/item/weekly-epide miological-updat eon- covid-19---10-august-2021

Zambrano-Monserrate MA, Ruano MA, Sanchez-Alcalde L (2020) Indirect effects of COVID-19 on the environment. Sci Total Environ 728:138813. https://doi.org/10.1016/j.scitotenv.2020.138813

Zhang Q, Jiang X, Tong D, Davis SJ, Zhao H, Geng G, Feng T, Zheng B, Lu Z, Streets DG (2017) Transboundary health impacts of transported global air pollution and international trade. Nature 543(7647):705-709. https://doi.org/10.1038/nature21712

Publisher's Note Springer Nature remains neutral with regard to jurisdictional claims in published maps and institutional affiliations. 